\title{
Erratum to: Navigating Community Institutions: Black Transgender Women's Experiences in Schools, the Criminal Justice System, and Churches
}

Louis F. Graham • Halley P. Crissman • Jack Tocco •

William D. Lopez • Rachel C. Snow • Mark B. Padilla

Published online: 2 April 2014

(C) Springer Science+Business Media New York 2014

\section{Erratum to: Sex Res Soc Policy}

DOI 10.1007/s13178-014-0144-y

The original version of this article unfortunately contained a mistake. All co-authors were omitted from the paper. The correct author group of this article is listed below.

The online version of the original article can be found at http://dx.doi.org/ 10.1007/s13178-014-0144-y.

L. F. Graham $(\bowtie)$

University of Massachusetts Amherst School of Public Health and Health Sciences, 715 North Pleasant Street, Amherst, MA 01003,

USA

e-mail: LFGraham@schoolph.umass.edu

H. P. Crissman

University of Michigan School of Medicine, Ann Arbor, MI, USA

J. Tocco $\cdot$ W. D. Lopez $\cdot$ R. C. Snow

Department of Health Behavior and Health Education, University of

Michigan School of Public Health, Ann Arbor, MI, USA

M. B. Padilla

Department of Global and Sociocultural Studies, Florida International University School of International and Public Affairs, Miami, FL, USA 